\title{
Saponification of High Molecular Weight Poly(vinyl pivalate)
}

\author{
Tohei Yamamoto, Shuji Yoda, Hirofumi Takase, \\ Tomoaki Saso, Osamu Sangen, Ryohei FukaE*, \\ Mikiharu KAMACHI ${ }^{* *}$, and Toshiaki SATO*** \\ Himeji Instituite of Technology, Shosha, Himeji 671-22, Japan \\ *Himeji Junior College, Shinzaikehonmachi, Himeji 670, Japan \\ **Faculty of Science, Osaka University, Machikaneyama, Toyonaka 560, Japan \\ ***Central Research Laboratories, KURARAY Co., Ltd., \\ Sakazu, Kurashiki 710, Japan
}

(Received August 15, 1990)

\begin{abstract}
The saponification of high molecular weight poly(vinyl pivalate) (PVP) was examined in several solvents, and PVA of $P_{n}=18000$ and $99 \%$ DS (degree of saponification) were obtained by saponification in the absence of oxygen with $\mathrm{KOH}$ ( 6 equivalents per monomer unit) in tetrahydrofuran at $60^{\circ} \mathrm{C}$ for $15 \mathrm{~min}$. In acetone, dioxane and methyl ethyl ketone, saponification was performed but marked degradation was observed. Saponification in benzene and dimethyl sulfoxide did not take place. $\mathrm{NaOH}$ was not useful because it cause marked degradation in any solvent.
\end{abstract}

KEY WORDS Saponification / High Molecular Weight / Poly(vinyl pivalate)

/ Poly(vinyl alcohol) / Solvent Effect /

Poly(vinyl pivalate) (PVP) having larger $P_{n}$ (average degree of polymerization) than $2 \times 10^{4}$ was obtained as described previously, ${ }^{1}$ and was expected to afford high molecular weight poly(vinyl alcohol) (PVA). Although a few studies have been reported on the saponification of PVP, ${ }^{2}$ it is very difficult to saponify PVP by these methods. New methods of saponification were examined and a good one was found as described in the present paper.

\section{EXPERIMENTAL}

\section{Poly(vinyl pivalate)}

In a $300 \mathrm{ml}$ Pyrex Kjeldahl flask $100 \mathrm{ml}$ of vinyl pivalate (VP), $10 \mathrm{ml}$ of LWZ (polyoxyethylene nonyl phenyl ether sodium sulfate, Kao Co.), $200 \mathrm{ml}$ of water and a teflon stirring bar were combined. The mixture was degased and the flask was sealed under vacuum. Then the flask was placed in a water-ethylene glycol bath at $0^{\circ} \mathrm{C}$, and with stirring the mixture was irradiated with a high pressure mercury lamp. After $70 \mathrm{~h}$ of irradiation, the mixture was poured into methanol and PVP precipitated. After filtration, the PVP was reprecipitated from methyl ethyl ketone and water, and was dried under vacuum at $60^{\circ} \mathrm{C}$.

\section{Saponification of PVP}

In a $300 \mathrm{ml}$ separable flask equipped with a reflux condenser and a dropping funnel $2.0 \mathrm{~g}$ of PVP was dissolved in $200 \mathrm{ml}$ of each solvent. The solution and $20 \mathrm{ml}$ of $25 \% \mathrm{KOH}$ (or $18 \%$ $\mathrm{NaOH}$ ) methanol solution in a dropping funnel were flushed with nitrogen. With stirring, the $\mathrm{KOH}$ solution was added slowly to the PVP solution and the mixture was kept at a fixed temperature (Table I) under nitrogen. The first precipitate appeared within $10 \mathrm{~min}$, and after a fixed time (Table I) the precipitate was filtered, washed with methanol and dried under vacuum. 
Table I. Results of saponification of poly(vinyl pivalate)

\begin{tabular}{|c|c|c|c|c|c|c|c|}
\hline \multirow{2}{*}{ Run } & \multirow{2}{*}{ Solvent } & \multirow{2}{*}{ Base $^{a}$} & \multirow{2}{*}{$\begin{array}{l}\text { Reaction } \\
\text { temp } /{ }^{\circ} \mathrm{C}\end{array}$} & \multirow{2}{*}{$\begin{array}{l}\text { Reaction } \\
\text { time/min }\end{array}$} & \multicolumn{2}{|c|}{$\mathrm{DS} / \%^{\mathrm{b}}$} & \multirow{2}{*}{$P_{n}^{\mathrm{e}}$} \\
\hline & & & & & $I^{c)}$ & $\mathrm{II}^{\mathrm{d})}$ & \\
\hline 1 & \multirow[t]{4}{*}{ Acetone } & \multirow[t]{2}{*}{$\mathrm{NaOH}$} & \multirow[t]{2}{*}{60} & 15 & 87 & \multirow[t]{4}{*}{87.8} & $2010^{\mathrm{f}}$ \\
\hline 2 & & & & 30 & 99 & & $2200^{f}$ \\
\hline 3 & & \multirow[t]{2}{*}{$\mathrm{KOH}$} & \multirow[t]{2}{*}{60} & 15 & 94 & & $9240^{\mathrm{f}}$ \\
\hline 4 & & & & 30 & 100 & & $8350^{\mathrm{f}}$ \\
\hline 5 & Benzene & $\mathrm{KOH}$ & 60 & 15 & - & \multirow[t]{2}{*}{2.0} & - \\
\hline 6 & Dimethyl sulfoxide & $\mathrm{KOH}$ & 60 & 15 & 0 & & - \\
\hline 7 & Dioxane & $\mathrm{KOH}$ & 60 & 15 & 97 & 97.8 & 4100 \\
\hline 8 & Methyl ethyl ketone & $\mathrm{KOH}$ & 60 & 15 & 99 & \multirow[t]{5}{*}{99.7} & 8200 \\
\hline 9 & Tetrahydrofuran & $\mathrm{KOH}$ & 60 & 10 & 97 & & 17800 \\
\hline 10 & & & & 15 & 99 & & $10600^{f}$ \\
\hline 11 & & & & 15 & 99 & & 18000 \\
\hline 12 & & & & 20 & 99 & & 17000 \\
\hline 13 & & & \multirow{5}{*}{50} & 30 & 99 & 98.8 & $10600^{f}$ \\
\hline 14 & & & & 10 & 80 & \multirow[t]{2}{*}{83.0} & 18100 \\
\hline 15 & & & & 20 & 92 & & 18700 \\
\hline 16 & & & & 30 & 99 & \multirow[t]{10}{*}{99.0} & 15800 \\
\hline 17 & & & & 40 & 99 & & 13200 \\
\hline 18 & & & 40 & 30 & 93 & & 13300 \\
\hline 19 & & & & 40 & 96 & & 13500 \\
\hline 20 & & & & 50 & 98 & & 14800 \\
\hline 21 & & & \multirow{5}{*}{60} & 60 & 99 & & 13500 \\
\hline 22 & & \multirow[t]{4}{*}{$\mathrm{NaOH}$} & & 30 & 83 & & $14500^{\mathrm{f}}$ \\
\hline 23 & & & & 60 & 95 & & $9900^{f}$ \\
\hline 24 & & & & 90 & 95 & & $8850^{\mathrm{f}}$ \\
\hline 25 & & & & 120 & 94 & & $8490^{\mathrm{f}}$ \\
\hline $\begin{array}{ll}{ }^{\mathrm{a}} & \mathrm{Ba} \\
{ }^{\mathrm{b}} & \mathrm{De} \\
\mathrm{c} & \mathrm{De} \\
{ }^{\mathrm{d}} & \mathrm{De} \\
\mathrm{e} & \mathrm{Est} \\
\mathrm{f} & P_{n}\end{array}$ & $\begin{array}{l}\text { mount: } 6 \text { equivalent } \\
\text { mined from weight los } \\
\text { mined from }{ }^{1} \mathrm{H} \text { NMR } \\
\text { ated from }[\eta] \text { of acety } \\
\text { PVP is } 25800 \text {, and tha }\end{array}$ & $\begin{array}{l}\text { monome } \\
\text { tectrum. } \\
\text { of the oth }\end{array}$ & $\begin{array}{l}\text { it mole. } \\
\text { d PVP). } \\
\text { s } 28300 \text {. }\end{array}$ & & & & \\
\hline
\end{tabular}

\section{Acetylation of PVA}

One $\mathrm{g}$ of PVA, $2 \mathrm{ml}(25 \mathrm{mmol})$ of pyridine, $20 \mathrm{ml}(0.2 \mathrm{~mol})$ of acetic anhydride and $20 \mathrm{ml}$ $(0.35 \mathrm{~mol})$ of acetic acid were added to a three-necked flask and with stirring, the mixture was kept at $100^{\circ} \mathrm{C}$ for $72 \mathrm{~h}$. The mixture was poured into cool water and PVAc was precipitated. The PVAc was filtered, reprecipitated from methanol and water, and dried under vacuum at $60^{\circ} \mathrm{C}$.

\section{Characteristics}

$P_{n}$ s of PVP and PVAc(acetylated PVA) were determined from the intrinsic viscosity $([\eta])$ measured in acetone at $25^{\circ} \mathrm{C}$ and in benzene at $30^{\circ} \mathrm{C}$, respectively. ${ }^{3}$

The degree of saponification (DS) was determined by weight loss after saponification and by the ratio of the tert-butyl proton and methylene proton peaks in the ${ }^{1} \mathrm{H}$ NMR spectrum of PVA (Figure 1).

\section{RESULTS AND DISCUSSION}

\section{Degree of Saponification and $P_{n}$}

The values of DS determined by weight loss are in good agreement with those determined by NMR (Table I), and these values are 


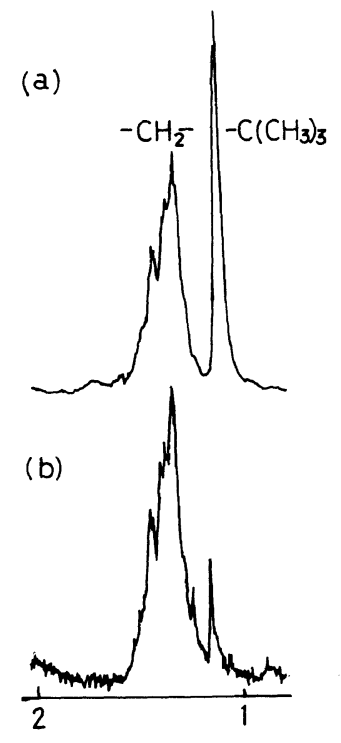

Figure 1. ${ }^{1} \mathrm{H}$ NMR spectra of PVA from PVP: (a) saponified with $\mathrm{NaOH}$ in acetone for $15 \mathrm{~min}$ at $60^{\circ} \mathrm{C}$ and (b) saponified with $\mathrm{KOH}$ in tetrahydrofuran for $30 \mathrm{~min}$ at $60^{\circ} \mathrm{C}$.

considered valid.

As the values of $P_{n}$ were estimated as PVAc from $[\eta]$ of acetylated polymer. $P_{n}$ s at low DS might not be valid, because the polymer had many pivalate groups. However, $P_{n}$ s of well saponified PVA are considered valid.

\section{Saponification in Acetone}

$P_{n}$ s of PVPs used for saponification were 25800 and 28300 . Initially, we tried to saponify PVP according to Nozakura's method [2], but the mixture became dark brown and marked degradation occurred, i.e. after one week reaction, $P_{n}$ decreased from 25800 to 2000 . Moreover complete saponification could not be attained. Then we tried the method of Imai et al., ${ }^{4}$ but PVP saponified was low. The reduction of PVP with $\mathrm{LiAlH}_{4}$ was possible but difficult to remove the $\mathrm{Li}$ and $\mathrm{Al}$ compounds.

The above saponification was carried out in the presence of oxygen. Saponification in the absence of oxygen was examined by flushing the system with nitrogen gas. Initially, the saponification of PVP was carried out in acetone under nitrogen by using $\mathrm{NaOH}$ as a base at $60^{\circ} \mathrm{C}$, and $99 \%$ DS was attained in 30 min without discoloration. However, $P_{n}$ of the PVA obtained decreased to 2200 (Table I, 2). Using $\mathrm{KOH}$ as a base, saponification was almost complete, and $P_{n}$ of PVA was high (Table I, 4).

\section{Solvent Effect}

To obtain PVA with higher $P_{n}$, other solvents were examined. Saponification was poor in benzene and dimethyl sulfoxide under nitrogen with $\mathrm{KOH}$ at $60^{\circ} \mathrm{C}$ (Table I, 5, 6). Although high DS was attained in methyl ethyl ketone and dioxane in $15 \mathrm{~min}$, degradation occurred (Table I, 7, 8). When tetrahydrofuran was the solvent, high DS and high $P_{n}$ were found.

\section{Saponification in Tetrahydrofuran}

In tetrahydrofuran, $99 \%$ DS was attained in $15 \mathrm{~min}$ under nitrogen with $\mathrm{KOH}$ at $60^{\circ} \mathrm{C}$, and $P_{n}$ of PVA was 18000 (Table I, 11). Although degradation after completion of saponification was not as high as in acetone, some was observed (Table I, 12). Thus, it is better to stop the reaction quickly.

Shiraishi et $a l .{ }^{5)}$ reported oxidative scission of the main chain of PVA in base. In these experiments, we propose that residual oxygen also causes degradation. To decrease oxygen that causes degradation, saponification at lower temperature was examined. However, it took 30 and $60 \mathrm{~min}$ to attain $99 \%$ DS at 50 and $40^{\circ} \mathrm{C}$, respectively, and PVA of higher $P_{n}$ could not be obtained (Table I, 16, 21). These results show that low activation energy for degradation, high reaction temperature, and short reaction time are favorable.

\section{Base Type and Concentration}

Saponification with $\mathrm{NaOH}$ in tetrahydrofuran at $60^{\circ} \mathrm{C}$ was unsatisfactory, because DS was only $95 \%$ even after $120 \mathrm{~min}$ and degradation occurred (Table I, 22-25).

Saponification with 1, 2, 3 or 6 equivalents 
Table II. Dependence of saponification of $\mathrm{PVP}^{\mathrm{a}}$ on $\mathrm{KOH}$ concentration in tetrahydrofuran at $60^{\circ} \mathrm{C}$

\begin{tabular}{ccc}
\hline KOH equivalent & $\mathrm{DS} / \%^{b}$ & $P_{n}$ \\
\hline 1.0 & 21 & - \\
2.0 & 50 & - \\
3.0 & 95 & 16060 \\
6.0 & 99 & 18000 \\
\hline
\end{tabular}

a $P_{n}$ of feed PVP is 28300.

b Determined from weight loss in $15 \mathrm{~min}$.

of $\mathrm{KOH}$ was examined to determine the effect on degradation (Table II).

Saponification with 1 and 2 equivalents was very slow, 3 equivalents were better but $\mathrm{Pn}$ was lower than that with 6 equivalents.

\section{CONCLUSION}

Saponification of high molecular weight PVP was performed at $60^{\circ} \mathrm{C}$ in $15 \mathrm{~min}$ with 6 equivalent of $\mathrm{KOH}$ per monomer unit in tetrahydrofuran in the absence of oxygen and
PVA with $P_{n}=18000$ was obtained. The main problem is oxidation which prevents complete saponification and causes degradation.

Acknowledgments. A part of this work was supported by a Grant-in-Aid from the Ministry of Education, Science, and Culture of Japan.

\section{REFERENCES}

1. T. Yamamoto, S. Yoda, O. Sangen, R. Fukae, and M. Kamachi, Polym. J., 21, 1053 (1989).

2. I. Sakurada and O. Yashizaki, Kobunshi Ronbushu, 14, 339 (1975); S. Nozakura, Y. Morishima, H. Iimura, and Y. Irie, J. Polym. Sci., Polym. Chem. Ed., 14, 759 (1976); Y. Morishima, W. Kim, and S. Nozakura, Polym. J., 8, 196 (1976).

3. J. Brandrup and E. H. Immergut, Ed., Polymer Handbook, John Wiely, New York, N. Y., 1967.

4. K. Imai, T. Shiomi, Y. Tezuka, T. Kawanishi, and T. Jin, J. Polym. Sci., Polym. Chem. Ed., 26, 1961 (1988).

5. M. Shiraishi and S. Matsumoto, Kobunshi Kagaku, 19, 722 (1962). 